\title{
Sinus Floor Augmentation Surgery Using Autologous Bone Grafts from Various Donor Sites: A Meta-Analysis of the Total Bone Volume
}

\author{
Reinoud J. Klijn, M.Sc., ${ }^{1,2}$ Gert J. Meijer, D.D.S., Ph.D., ${ }^{1,3}$ Ewald M. Bronkhorst, Ph.D., ${ }^{4}$ \\ and John A. Jansen, D.D.S., Ph.D.
}

Background: To date, no studies have been published that evaluated histomorphometric data from a large number of patients while comparing different sites and methods of autologous bone grafting in sinus floor augmentation procedures. A meta-analysis of the English literature from January 1995 till April 2009 was carried out.

Materials and Methods: PubMed search engine and the following journals were explored: Clinical Oral Implant Research, International Journal of Oral and Maxillofacial Implants, International Journal of Periodontics and Restorative Dentistry, and the Journal of Periodontology.

Results: Out of 147 titles, according to our criteria, 25 articles were left for analysis. The majority were prospective controlled studies (21) and 2 randomized clinical trials, 1 pilot study and 1 case series. A reference value of $47 \%$ for total bone volume (TBV) was found while using iliac bone grafting as a standard. Use of intraoral bone grafts increases the TBV, with $11 \%$ for chin bone and $14 \%$ for bone grafted from other intraoral sites. Particulation of the bone graft has a negative effect on the TBV of $18 \%$. Surprisingly, no correlation between TBV and the time of graft healing was found. Histological section thickness seemed to be a significant variable, as every micron increase of section thickness leads to an increase of $0.4 \%$ of TBV.

Conclusions: Bone grafting from the iliac crest resulted in a significantly lower TBV compared with intraoral bone grafting. However, due to the limited availability of intraoral bone to be harvested, iliac grafts still have to be considered the gold standard in augmenting the severely atrophic maxilla.

\section{Introduction}

$\mathbf{P}$ LACEMENT OF DENTAL IMPLANTS requires the presence of adequate bone height en width. In case of lack of bone volume, additional surgical techniques are needed to generate primary implant stability. ${ }^{1}$ If extensive alveolar defects are present, onlay or inlay grafting procedures are advised. ${ }^{1-7}$ To allow implant placement in the lateral part of the maxilla, sinus floor augmentation has become a routine procedure, ${ }^{8-11}$ resulting in an implant survival rate of $90 \%$ for 3-5 years. ${ }^{7,12}$ In this procedure, first a small window is created in the lateral wall of the maxilla. Subsequently, the sinus epithelium is elevated and the created space is filled with a grafting material. For sinus floor augmentations, autologous bone is the most common used material and, as such, is still considered the gold standard, ${ }^{7,13}$ although numerous alternative materials have been used with variable results.
Both intraoral and extraoral sites can be considered donor sites. ${ }^{14}$ As such, the chin, retromolar region, iliac crest, calvarium, tibia, and rib have been described. ${ }^{15,16}$ An advantage of intraoral donor sites is that the graft can be harvested under local anesthesia. However, the amount of bone that can be gained is limited. If larger bone volumes are needed, the iliac crest is the most common used donor site. Alternatives such as bone substitutes do not provide the cellular elements necessary for osteogenesis, as they are only osteoconductive. ${ }^{17,18}$ For bone transplants, in addition to donor sites, other variables may influence the final outcome. ${ }^{9}$ For example, some studies advise to apply a resorbable or nonresorbable barrier membrane over the sinus graft osteotomy site. ${ }^{19-22}$

Till now, no studies have been published that evaluated histological and histomorphometric data from a large amount of patients inventorying these variables. To answer the question as to which approach is the best in using autologous

\footnotetext{
${ }^{1}$ Department of Periodontology and Biomaterials, Radboud University Nijmegen Medical Center, Nijmegen, The Netherlands.

${ }^{2}$ Technical Medicine, University of Twente, Enschede, The Netherlands.

Departments of ${ }^{3}$ Oral and Maxillofacial Surgery and ${ }^{4}$ Preventive and Curative Dentistry, Radboud University Nijmegen Medical Center, Nijmegen, The Netherlands.
} 
bone grafts after sinus floor augmentation surgery, a metaanalysis was conducted.

\section{Materials and Methods}

\section{Search protocol and selection of articles}

An online and manual search of the Medline database was conducted from January 1995 till April 2009, using the PubMed search machine while entering the following search terms: "(Maxillary) Sinus augmentation or (Maxillary) Sinus lift," "human or clinical or patient," and "histology or histomorphometry or histomorphometric." A hand search was performed in the following journals: Clinical Oral Implant Research, International Journal of Oral and Maxillofacial Implants, International Journal of Periodontics and Restorative Dentistry, and the Journal of Periodontology. Additionally, the references of the retrieved articles were searched. The results were limited to humans as well as articles published in the English literature. Articles were regarded eligible if they met the following inclusion criteria: (1) The target population comprised adult patients suffering from maxillary atrophy; (2) The intervention was maxillary sinus floor augmentation using an autologous bone graft; and (3) Histomorphometric data about bone formation were present. Each potentially appropriate study included at least two patients per specific treatment in whom an autologous bone graft was used as the only augmentation material after conducting the maxillary sinus floor elevation procedure.

Articles were excluded if they reported only one patient or if histomorphometric data were absent. Each retrieved citation was reviewed by two independently working reviewers. Most articles were excluded on basis of information provided by the title or abstract. If the citation could not be excluded unequivocally, the complete report was obtained by the two reviewers. Any disagreement between them was resolved by a consensus. The two reviewers extracted from each eligible article all pertinent information regarding patients' demographics, maxillary sinus floor augmentation surgery, and outcome data. Demographic data included age, sex, follow-up rate, and duration. Also, the number of patients, the number of treated maxillary sinuses, possible usage of collagen or nonresorbable membranes, further operative data, and all results from histomorphometry were noted. To ensure consistency of the results for the included studies, clear definitions of outcome were given. For example, total bone volume (TBV) was based on histomorphometric data as a percentage of the whole field of view.

Subsequently, the included studies concerning data on age, sex, immediate or delayed implant placement, membrane usage, biopsy time, histological section thickness, graft site, particulated versus block grafting technique, and TBV were carefully analyzed. Where adequate data were available, subgroups of similar interventions with respect to, for example, surgical techniques, donor site, and membrane and biopsy time were isolated and subjected to backward linear regression to identify them as possible sources of covariance.

\section{Meta-analysis}

Linear regression, a form of meta-analysis, was performed to determine the effect of the independent variables "age," "donor site location," "block graft," "particulated graft," presence of a "resorbable barrier membrane" over the lateral window, "simultaneous and delayed" implant placement, "biopsy time," and "histological section thickness" on the histomorphometric outcome after autologous bone grafting in maxillary sinus floor augmentation. The amount of TBV was used as the dependent variable. To evaluate the influence of "biopsy time" on the histomorphometric data outcome, the subgroups were divided into three different groups: $0-4$ months, $4-6.5$ months, and longer than 6.5 months. To reduce the initial model, stepwise backward linear regression was applied with a threshold for the $p$-value of above 0.1 for removing a variable from the model. The overall averages were controlled for study characteristics and can, therefore, be considered metaeffect sizes. Thus, more powerful estimates of the true effect sizes than those derived in a single study under a given single set of assumptions and conditions can be given.

\section{Included studies and donor sites}

The basis search provided 147 titles for consideration (Table 1). Twenty-five articles met our inclusion criteria. Frequently (17), autologous bone volume percentages were extracted from comparative experiments in which they were used as a control group. The majority of these 25 articles were prospective controlled studies (21) and 2 randomized clinical trials, 1 pilot study and 1 case series. Only two prospective randomized clinical trials met the inclusion criteria (Table 2). Of the 25 articles derived from the main search, 15 discussed the use of autogenous bone from the iliac crest for augmentation of the maxillary sinus floor. The use of chin bone as grafting material was found in 6 of the 25 articles, whereas the use of intraoral bone, the chin excluded, was investigated in 7 of the 25 articles.

\section{Results}

\section{Donor site}

lliac. Bone grafts were harvested from the anterior as well as the posterior iliac crest. From these articles, adequate data were found to discern 26 individual subgroups describing 273 sinus floor augmentation procedures (Table 3 ). Histomorphometric results from biopsies were described for sinus floor augmentation procedures up to 12 months after initial surgery. Bone blocks, particulated bone grafts, or a combination of both were used. Several authors combined autogenous bone with platelet rich plasma (PRP), ${ }^{23-25}$ but those subgroups were left out of consideration. At the moment of sinus floor augmentation, bone grafts showed a TBV of approximately $60 \%,{ }^{26,27}$ varying from $32.5 \%$ to $78.4 \%$. After backward linear regression, there was significant evidence that the use of iliac bone grafts would result in a lower amount of TBV than intraoral bone grafting.

Intraoral bone: Chin. From the included articles, 13 different subgroups could be identified as describing the use of

Table 1. Literature SeArch

"Sinus augmentation" or "sinus lift"

428 hits

And ("human" or "patient" or "clinical")

And ("histology" or "histomorphometric"

401 hits

or "histomorphometry") 
Table 2. Overview of the Analyzed Articles

\begin{tabular}{|c|c|c|c|c|}
\hline Author & Reference & Type & Graft and donor site & $\begin{array}{c}\text { Total number } \\
\text { of treated patients }\end{array}$ \\
\hline Barone et al. (2005) & 22 & $\mathrm{RCT}$ & Autogenous iliac & 18 \\
\hline Consolo et al. (2007) & 23 & CT & Autogenous iliac & 16 \\
\hline Crespi et al. (2007) & 21 & $\mathrm{CT}$ & Autogenous iliac or miscellaneous & 16 \\
\hline Crespi et al. (2009) & 36 & $\mathrm{CT}$ & Autogenous miscellaneous & 15 \\
\hline Gerressen et al. (2009) & 43 & $\mathrm{CT}$ & Autogenous iliac & 15 \\
\hline Groeneveld et al. (1999) & 46 & CS & Autogenous iliac & 12 \\
\hline Hallman et al. (2002) & 37 & $\mathrm{CT}$ & Autogenous miscellaneous & 21 \\
\hline John and Wenz (2004) & 47 & $\mathrm{CT}$ & Autogenous chin & 38 \\
\hline Le Lorc'h-Bukiet et al. (2005) & 35 & $\mathrm{CT}$ & Autogenous chin or miscellaneous & 24 \\
\hline Lorenzetti et al. (1998) & 27 & $\mathrm{CT}$ & Autogenous iliac or chin & 13 \\
\hline Lundgren et al. (1996) & 14 & $\mathrm{CT}$ & Autogenous chin or miscellaneous & 10 \\
\hline Pejrone et al. (2002) & 26 & CT & Autogenous iliac & 13 \\
\hline Peleg et al. (2004) & 20 & $\mathrm{CT}$ & Autogenous miscellaneous & 156 \\
\hline Raghoebar et al. (2005) & 24 & $\mathrm{CT}$ & Autogenous iliac & 5 \\
\hline Scarano et al. (2006) & 34 & $\mathrm{CT}$ & Autogenous miscellaneous & 94 \\
\hline Suba et al. (2006) & 48 & $\mathrm{CT}$ & Autogenous iliac & 17 \\
\hline Szabo et al. (2001) & 44 & $\mathrm{CT}$ & Autogenous iliac & 4 \\
\hline Szabo et al. (2005) & 49 & $\mathrm{RCT}$ & Autogenous iliac & 20 \\
\hline Tadjoedin et al. (2000) & 28 & $\mathrm{CT}$ & Autogenous iliac & 10 \\
\hline Thor et al. (2007) & 25 & $\mathrm{CT}$ & Autogenous iliac & 11 \\
\hline Turunen et al. (2004) & 50 & $\mathrm{CT}$ & Autogenous iliac & 17 \\
\hline van den Bergh et al. (2000) & 42 & CPS & Autogenous iliac & 6 \\
\hline Zerbo et al. (2003) & 19 & $\mathrm{CT}$ & Autogenous chin & 19 \\
\hline Zerbo et al. (2004) & 29 & $\mathrm{CT}$ & Autogenous chin & 9 \\
\hline Zijderveld et al. (2005) & 33 & $\mathrm{CT}$ & Autogenous chin & 10 \\
\hline
\end{tabular}

$\mathrm{RCT}$, randomized clinical trial; CT, clinical trial; CPS, clinical pilot study; CS, case series.

Table 3. Iliac Bone Grafting

\begin{tabular}{|c|c|c|c|c|c|c|c|c|}
\hline Author & Reference & $\begin{array}{l}\text { Number } \\
\text { of sinuses }\end{array}$ & $\begin{array}{l}\text { Mean } \\
\text { age }\end{array}$ & $\begin{array}{l}\text { Particulated } \\
\text { or block }\end{array}$ & $\begin{array}{l}\text { Simultaneous } \\
\text { (1) and delayed } \\
\text { (2) implant } \\
\text { placement }\end{array}$ & $\begin{array}{l}\text { Mean } \\
\text { biopsy } \\
\text { time } \\
\text { (months) }\end{array}$ & $\begin{array}{c}\text { Slice } \\
\text { thickness }\end{array}$ & $\begin{array}{l}\text { Mean total } \\
\text { bone volume } \\
(\%)\end{array}$ \\
\hline Pejrone et al. (2002) & 26 & 26 & 57 & Block & 1 & 0 & 7 & $59.3 \pm 6.3$ \\
\hline Lorenzetti et al. (1998) & 27 & 8 & 51.75 & $\begin{array}{l}\text { Block and } \\
\text { particulated }\end{array}$ & 1 & 0 & 8 & 60 \\
\hline Thor et al. (2007) & 25 & 11 & 55 & Particulated & 2 & 3 & 12.5 & $11 \pm 3$ \\
\hline Raghoebar et al. (2005) & 24 & 5 & 58.4 & $\begin{array}{l}\text { Block and } \\
\text { particulated }\end{array}$ & 2 & 3 & 2 & $41.1 \pm 8.3$ \\
\hline Consolo et al. (2007) & 23 & 2 & 47 & Particulated & 2 & 4 & 5 & $26 \pm 5.2$ \\
\hline Tadjoedin et al. (2000) & 28 & 3 & 54 & Particulated & 2 & 4 & 5 & $40.94 \pm 3.32$ \\
\hline Consolo et al. (2007) & 23 & 2 & 47 & Particulated & 2 & 5 & 5 & $29.2 \pm 4$ \\
\hline Crespi et al. (2007) & 21 & 6 & 51.4 & Particulated & 2 & 5 & 30 & $34 \pm 21$ \\
\hline Tadjoedin et al. (2000) & 28 & 3 & 54 & Particulated & 2 & 5 & 5 & $42.24 \pm 4.48$ \\
\hline Barone et al. (2005) & 22 & 18 & 46.7 & Particulated & 2 & 5 & 50 & $70 \pm 19.9$ \\
\hline Gerressen et al. (2009) & 43 & 15 & 54.9 & Particulated & 2 & 5.2 & & $29.35 \pm 4.04$ \\
\hline Gerressen et al. (2009) & 43 & 15 & 54.9 & Particulated & 2 & 5.2 & & $37.87 \pm 12.18$ \\
\hline Thor et al. (2007) & 25 & 11 & 55 & Particulated & 2 & 6 & 12.5 & $13 \pm 6$ \\
\hline Groeneveld et al. (1999) & 46 & 3 & 55 & Particulated & 2 & 6 & 5 & $26.2 \pm 5.9$ \\
\hline van den Bergh et al. (2000) & 42 & 3 & 50 & Particulated & 2 & 6 & 3 & $26.6 \pm 5.9$ \\
\hline Consolo et al. (2007) & 23 & 2 & 47 & Particulated & 2 & 6 & 5 & 29 \\
\hline Szabo et al. (2001) & 44 & 4 & 52 & Particulated & 2 & 6 & & $37.05 \pm 8.66$ \\
\hline Szabo et al. (2005) & 49 & 20 & 52 & Particulated & 2 & 6 & 5 & $38.34 \pm 7.4$ \\
\hline Tadjoedin et al. (2000) & 28 & 3 & 54 & Particulated & 2 & 6 & 5 & $43.65 \pm 2.38$ \\
\hline Lorenzetti et al. (1998) & 27 & 8 & 51.75 & $\begin{array}{l}\text { Block and } \\
\text { particulated }\end{array}$ & 2 & 6 & 8 & 53 \\
\hline Pejrone et al. (2002) & 26 & 26 & 57 & Block & 2 & 6 & 7 & $54.1 \pm 6.8$ \\
\hline Suba et al. (2006) & 48 & 17 & 52 & Particulated & 2 & 6.5 & 5 & $34.7 \pm 11.86$ \\
\hline Consolo et al. (2007) & 23 & 2 & 47 & Particulated & 2 & 7 & 5 & 20 \\
\hline Turunen et al. (2004) & 50 & 17 & 50 & $\begin{array}{l}\text { Block and } \\
\text { particulated }\end{array}$ & 2 & 7 & 20 & $25.1 \pm 7.2$ \\
\hline Turunen et al. (2004) & 50 & 17 & 50 & $\begin{array}{l}\text { Block and } \\
\text { particulated }\end{array}$ & 2 & 12 & 20 & $25.1 \pm 6.3$ \\
\hline Pejrone et al. (2002) & 26 & 26 & 57 & Block & 2 & 12 & 7 & $63.9 \pm 8.7$ \\
\hline
\end{tabular}


Table 4. Intraoral Chin Bone Grafting

\begin{tabular}{|c|c|c|c|c|c|c|c|c|}
\hline Author & Reference & $\begin{array}{l}\text { Number } \\
\text { of sinuses }\end{array}$ & $\begin{array}{l}\text { Mean } \\
\text { age }\end{array}$ & $\begin{array}{l}\text { Particulated } \\
\text { or block }\end{array}$ & $\begin{array}{l}\text { Simultaneous (1) } \\
\text { and delayed (2) } \\
\text { implant placement }\end{array}$ & $\begin{array}{c}\text { Mean biopsy } \\
\text { time } \\
\text { (months) }\end{array}$ & $\begin{array}{c}\text { Slice } \\
\text { thickness }\end{array}$ & $\begin{array}{c}\text { Mean total } \\
\text { bone volume } \\
(\%)\end{array}$ \\
\hline Lundgren et al. (1996) & 14 & 10 & 53 & Block & 1 & 0 & 10 & $58 \pm 19$ \\
\hline Lorenzetti et al. (1998) & 27 & 3 & 52.33 & Particulated & 1 & 0 & 8 & 65.6 \\
\hline Lorenzetti et al. (1998) & 27 & 3 & 51.33 & Block & 1 & 0 & & 65.6 \\
\hline Zerbo et al. (2003) & 19 & 5 & 39.2 & Block & 2 & 3 & 5 & 39.38 \\
\hline Zerbo et al. (2003) & 19 & 6 & 32.33 & Block & 2 & 4 & 5 & 39.78 \\
\hline Lorenzetti et al. (1998) & 27 & 3 & 51.33 & Block & 2 & 4 & 8 & 62.9 \\
\hline John and Wenz (2004) & 47 & 4 & 52 & Particulated & $1 / 2$ & 5 & 50 & $53.5 \pm 2.52$ \\
\hline Lundgren et al. (1996) & 14 & 10 & 53 & Particulated & 2 & 6 & 10 & $40 \pm 12$ \\
\hline Zerbo et al. (2003) & 19 & 3 & 33.67 & Block & 2 & 6 & 5 & 40.9 \\
\hline Zerbo et al. (2004) & 29 & 2 & 53.8 & Particulated & 2 & 6 & 5 & $41 \pm 10$ \\
\hline Zijderveld et al. (2005) & 33 & 3 & 53.83 & Particulated & 2 & 6 & 5 & $41 \pm 10$ \\
\hline Lorenzetti et al. (1998) & 27 & 3 & 52.33 & Particulated & 2 & 10.6 & 8 & 69.3 \\
\hline Lundgren et al. (1996) & 14 & 10 & 53 & Particulated & 2 & 12 & 10 & $48 \pm 10$ \\
\hline
\end{tabular}

chin bone. In 7 of them, autologous bone was used as particulate, and in 6 of them, it was used as bone blocks, with a total of 65 sinus floor augmentation procedures (Table 4). These studies evaluated biopsies taken both immediately after sinus floor augmentation and after a healing period with a range of 3-12 months. At the moment of initial surgery, a TBV of $58-65 \%$ was presented. ${ }^{14,27}$ After healing (3-12 months), the TBV varied between $39.38 \%$ and $69.3 \%$. After backward linear regression, there was significant evidence that the use of chin bone grafts would have a positive effect on the amount of TBV as compared with iliac bone grafts. Chin bone grafts increase the TBV by $10.7 \%$ at a confidence interval of $[1.3 \%, 20.1 \%]$ and a $p$-value of 0.026 (Table 8 ).

Intraoral bone: Miscellaneous. Seven subgroups could be discerned within the included articles describing the histomorphometric results from 183 augmented sinuses grafted with intraoral bone, excluding the chin. The anterior maxillary wall, the zygomatico-maxillary buttress, the lateral mandibular body, and the ramus were chosen as intraoral donor sites (Table 5). Though not of intraoral origin, parietal bone also was included in this group. All studies described results from particulated bone grafts and no bone blocks were used. Biopsies were examined immediately after initial surgery and after a healing period of 4.5-12.5 months. At the moment of initial augmentation surgery, bone grafts presented a TBV of $45 \% .{ }^{14}$ After healing, TBV differed within a range of $39.38-69.3 \%$ over time. After statistical analysis, there was significant evidence that the use of intraoral bone grafts had a positive effect on the amount of TBV as compared with iliac bone grafts. Usage of intraoral bone results in an increase of $13.5 \%$ bone with a confidence interval of $[2.1 \%, 24.9 \%]$ and a $p$-value of 0.021 . No significant differences between the various intraoral donor sites, including chin and bone, could be found.

Membrane. The use of a barrier membrane over the lateral wall to protect the autologous bone graft was investigated in 4 out of the 25 articles. The iliac crest, chin, and other intraoral bone sites were donor sites for the bone grafts. From these articles, seven subgroups could be identified as describing the histomorphometric results from 145 augmented sinuses (Table 6). Patients had a mean age between 32.3 and 51.4 years. In all subgroups, a collagen barrier membrane was placed over the graft according to the principal of guided bone regeneration. ${ }^{19-22}$ Further, Peleg et al. ${ }^{20}$ described the use of lypophilized duramater for such a purpose. Core biopsies were obtained after a healing period of 3-6 months with a mean TBV of 31.5-70\%. After backward linear regression, there was no significant evidence whether the use of a resorbable membrane over the lateral window would have a positive or negative effect on the amount of TBV.

\section{Statistical analysis}

The 11 variables entered into the regression model as well as their $p$-values are shown in Table 7 . The $R^{2}$ for the full

Table 5. Intraoral Miscellaneous Bone Grafting

\begin{tabular}{|c|c|c|c|c|c|c|c|c|}
\hline Author & Reference & $\begin{array}{l}\text { Number } \\
\text { of sinuses }\end{array}$ & $\begin{array}{c}\text { Mean } \\
\text { age }\end{array}$ & $\begin{array}{l}\text { Particulated } \\
\text { or block }\end{array}$ & $\begin{array}{l}\text { Simultaneous (1) } \\
\text { and delayed (2) } \\
\text { implant placement }\end{array}$ & $\begin{array}{l}\text { Mean biopsy } \\
\text { time (months) }\end{array}$ & $\begin{array}{c}\text { Slice } \\
\text { thickness }\end{array}$ & $\begin{array}{c}\text { Mean total } \\
\text { bone volume } \\
(\%)\end{array}$ \\
\hline Lundgren et al. (1996) & 14 & 10 & 53 & Particulated & 1 & 0 & 10 & $45 \pm 15$ \\
\hline Peleg et al. (2004) & 20 & 97 & & Particulated & & 4.5 & & 31.5 \\
\hline Le Lorc'h-Bukiet et al. (2005) & 35 & 24 & 59 & Particulated & 2 & 5 & 4 & $49.4 \pm 18.4$ \\
\hline Crespi et al. (2007) & 21 & 10 & 51.4 & Particulated & 2 & 5 & 30 & $69.7 \pm 16.1$ \\
\hline Crespi et al. (2009) & 36 & 15 & 54.2 & Particulated & 2 & 5 & 30 & $78.4 \pm 16.72$ \\
\hline Scarano et al. (2006) & 34 & 16 & 61 & Particulated & 2 & 6 & 30 & $40.1 \pm 3.2$ \\
\hline Hallman et al. (2002) & 37 & 11 & 54 & Particulated & 2 & 12.5 & 10 & $37.3 \pm 31.3$ \\
\hline
\end{tabular}


Table 6. Membrane Use

\begin{tabular}{lcccllccc}
\hline & \multicolumn{1}{c}{$\begin{array}{c}\text { Number } \\
\text { Author }\end{array}$} & $\begin{array}{c}\text { Mean } \\
\text { Reference }\end{array}$ & Donor site & Membrane & $\begin{array}{c}\text { Mean biopsy } \\
\text { time (months) }\end{array}$ & $\begin{array}{c}\text { Slice } \\
\text { thickness }\end{array}$ & $\begin{array}{c}\text { Mean total } \\
\text { bone volume } \\
\text { (\%) }\end{array}$ \\
\hline Zerbo et al. (2003) & 19 & 5 & 39.2 & Chin & Collagen & 3 & 5 & 39.38 \\
Zerbo et al. (2003) & 19 & 6 & 32.33 & Chin & Collagen & 4 & 5 & 39.78 \\
Peleg et al. (2004) & 20 & 97 & & Intraoral & Collagen & 4.5 & 30 & 34.5 \\
Crespi et al. (2007) & 21 & 6 & 51.4 & Iliac crest & Collagen & 5 & 51 \\
Crespi et al. (2007) & 21 & 10 & 51.4 & Intraoral & Collagen & 5 & 30 & $69.7 \pm 16.1$ \\
Barone et al. (2005) & 22 & 18 & 46.7 & Iliac crest & Collagen & 5 & 50 & $70 \pm 19.9$ \\
Zerbo et al. (2003) & 19 & 3 & 33.67 & Chin & Collagen & 6 & 5 & 40.9 \\
\hline
\end{tabular}

model (all 11 variables) was 0.475 . After removal of nonsignificant variables by backward selection, five significant variables remained in the model. All five variables showed a significance of $p<0.1$ with a model $R^{2}$ of 0.453 , thus explaining the variation in TBV, as described in the histomorphometric results. In Table 8 , the results of the linear regression analysis of the predicting variables on TBV are given. Only the variables "patients age," "intra oral chin bone," "intra oral miscellaneous bone," "particulated" grafts, and "histological section thickness" remained in the model. All effects have been corrected for different parameters inside the model by backward regression. After linear backward regression, a reference value of 46.5 for TBV was found.

Patient's age. For each year the patient is above 50, an increase of $0.84 \%$ of the TBV is to be expected with a confidence interval of $[0.07 \%, 1.61 \%]$.

Donor site. Usage of an intraoral chin bone graft leads to an increase of $10.7 \%$ of the TBV with a confidence interval of $[1.3 \%, 20.1 \%]$, whereas usage of bone from miscellaneous intraoral sites leads to an increase of $13.5 \%$ bone with a confidence interval of $[2.1 \%, 24.9 \%]$. Therefore, iliac bone grafts result in a significantly lower amount of TBV. Taken into account that the confidence intervals of intraoral and chin bone grafts had a significant overlap, the difference between the donor sites regarding amount of TBV was not statistically significant. All data were divided into three different biopsy time groups: $0 \leq t \leq 4$ months, $4<t \leq 6.5$ months, and $t>6.5$ months. There was no significant evidence that the amount of TBV was influenced by either immediate or delayed implant placement or graft healing time, thus the biopsy time of the samples. There was no evidence whether the use of a resorbable membrane over the lateral window had any effect, positive or negative, on the amount of TBV.

Particulated and block grafting. Particulation of the bone graft showed a negative effect on TBV, as a decrease of $-17.8 \%$ was seen with a confidence interval of $[-28.2 \%$, $-7.5 \%]$. Block grafting had no significant positive or negative influence on the histomorphometric outcome.

Histological section thickness. Histological section thickness seemed to be a significant variable to TBV in histomorphometric coupes. Every micrometer increase of section thickness leads to an increase of $0.387 \%$ of the TBV with a confidence interval of $[0.066 \%, 0.708 \%]$.

\section{Discussion}

Sinus floor augmentation surgery has become a routine procedure that provides adequate bone volume for placement, stabilization, and osteointegration of dental implants. Intraoral defects, which need to be reconstructed to allow dental implant placement, are ideal test sites to evaluate the grafted material. Before preparation of the implant bed to

Table 7. Full Linear Regression Model, $R^{2}=0.475$; Adjusted $R^{2}=0.316$

\begin{tabular}{lcccc}
\hline & $\begin{array}{c}\text { Unstandardized } \\
\text { coefficients B }\end{array}$ & Significancy & \multicolumn{2}{c}{$95 \%$ confidence interval for B } \\
\cline { 4 - 5 } Model 1 & 35.8 & 0.305 & -34.1 & Upper bound \\
\hline Constant & 1.019 & 0.083 & -0.139 & 105.7 \\
Age centered & 10.6 & 0.049 & 0.05 & 2.178 \\
Intraoral chin & -24.7 & 0.021 & -45.5 & -3.9 \\
Particulate & -8.4 & 0.372 & -27.3 & 10.5 \\
Block & 8.7 & 0.599 & -24.5 & 41.9 \\
Implantology & 0.9 & 0.878 & -10.7 & 12.5 \\
Biopsy 0-4 months & 2.0 & 0.752 & -10.8 & 14.8 \\
Biopsy > 6.5 months & 3.8 & 0.689 & -15.6 & 23.4 \\
Membrane & 10.9 & 0.111 & -2.7 & 24.34 \\
Intraoral miscellaneous & 0.422 & 0.067 & -0.030 & 0.875 \\
Slice thickness & & & &
\end{tabular}

Dependent variable: total bone volume. 
Table 8. Linear Backward Regression Final Model, $R^{2}=0.453$; Adjusted $R^{2}=0.380$

\begin{tabular}{lcccc}
\hline & & & \multicolumn{2}{c}{$95 \%$ confidence interval for B } \\
\cline { 2 - 5 } Final model & $\begin{array}{c}\text { Unstandardized } \\
\text { coefficients } B\end{array}$ & Significancy & Lower bound & Upper bound \\
\hline Constant & 46.5 & 0.000 & 36.77 & 56.39 \\
Age centered & 0.838 & 0.034 & 0.066 & 1.61 \\
Intraoral chin & 10.7 & 0.026 & -28.2 & -7.5 \\
Particulate & -17.8 & 0.001 & 2.1 & 24.9 \\
Intraoral miscellaneous & 13.5 & 0.021 & 0.066 & 0.708 \\
Slice thickness & 0.387 & 0.020 & \\
\hline
\end{tabular}

Dependent variable: total bone volume.

install dental implants, a biopsy of the reconstructed area can be easily taken, which implicates no extra burden for the patient. ${ }^{28,29}$ Moreover, all surgical procedures, except the extraoral grafting procedure, can be performed under local anesthesia. The selection of a donor site is often made on considerations driven by the quantity needed for the individual case. In the selected papers, various bone substitutes with different results were used to increase the grafting volume. However, bone substitutes do not provide the cellular elements necessary for osteogenesis, as they are solely osteoconductive. Autologous bone grafts are considered the gold standard. This conclusion, however, is only based on implant survival, whereas bone quality in the grafted area is often left out of consideration. ${ }^{8}$ The aim of this study was to give a powerful estimate of the true effect of different variables on the TBV in sinus floor augmentation surgery, using autologous bone graft derived from various donor sites. Predominantly, prospective controlled trials were described (21); only 2 randomized controlled trials met the inclusion criteria, including a pilot study and 1 case series. Backward linear regression was performed. The only dependent variable to assess the quality of the bone graft was the TBV, due to the general absence of other histomorphometric indices in the studies. Only the variables "patient age," "intra oral chin bone," "intra oral miscellaneous bone," "particulated grafts," and "slice thickness" seemed to have a significant effect and remained in the model.

\section{Patient age}

At a first glance, it seems surprising that for each year the patient gets older, an increase of $0.84 \%$ of the TBV is to be expected. However, one should realize that bone remodeling, for example, the quantitative and qualitative changes in bone tissue and in bones themselves, occurs not only during growth but also during normal aging. These changes in the elderly result in a loss of bone mass and bone strength, ${ }^{30}$ as a sign of decreased ability to regenerate bone. No proper explanation can be given for the slight increase in TBV for each year the patient gets older.

\section{Donor site}

Intraoral grafting from miscellaneous sites, including the chin region, offers the advantage of local instead of general anesthesia, a limited distance between donor site and augmentation site and the avoidance of cutaneous scars. Although the amount of bone to be gained is rather low, chin bone can be grafted not only in particulate but also in block form. Predominantly, autologous bone grafts obtained from the iliac crest were investigated. Although several drawbacks were reported, including donor site morbidity and prolonged operation time, a relatively larger amount of bone is available that can be harvested in multiple forms (particles, strips, and blocks). In this meta-analysis, it is shown that bone grafts from the iliac crest lead to significantly lower bone volume than chin bone. Some argue that embryology plays a role; ectomesenchymal mandibular bone grafts survive better than mesenchymal iliac bone grafts in an ectomesenchymal environment as the maxillary sinus. ${ }^{32}$ Further, the mechanical stress distribution on the bone graft will be different or lost after grafting of the maxillary sinus, so resorption may occur more rapidly. In addition, Lundgren et al. concluded that the advantage of simultaneously inserting implants and performing sinus floor augmentation (immediate placement) is that loading and subsequent preservation of the chin bone graft can be initiated earlier. ${ }^{14}$ However, they also showed an increased bone volume fraction in the graft throughout the healing time, even though the transplanted bone grafts received no stimulatory loading forces. ${ }^{14}$

It has been shown that also bone grafts, harvested from intraoral sites other than the chin, lead to a significantly higher TBV as compared with iliac crest bone. Complications related to the harvesting of intraoral bone are seldom reported, especially using the shaving technique described by Peleg et al. ${ }^{20}$ Scarano et al. compared different materials in maxillary sinus floor augmentation, including intraoral autologous bone grafts. ${ }^{34}$ Almost all autologous bone particles were completely surrounded by newly formed bone. ${ }^{34}$ A low resorption process was present and the graft showed a pattern similar to that of host bone. ${ }^{34}$ Le Lorc'h-Bukiet et al. concluded that bone remodeling seems to be more active in the cancellous portion than in the cortical portion. ${ }^{35}$ After 10 months of grafting, the bone chips were incorporated in newly formed bone and almost completely resorbed. ${ }^{35}$ Crespi et al. used autologous bone from the ascending ramus of the mandible. After 5 months, biopsies were taken and both lamellar and woven bone were observed. ${ }^{36}$ Gene expression profiles revealed expression of certain genes, indicative of osteoblast differentiation and bone formation. ${ }^{36}$ Hallman et al. allowed autologous bone graft to heal for an average time of 7.5 months and advocated the placement of extra microimplants to evaluate the bone-implant contact interface without interfering with the healing of standard implants. ${ }^{37}$ This technique also made it possible to correlate the histological and histomorphometric findings with the clinical outcome of the standard implants placed in the same area. ${ }^{37}$ 
In 2003, Wallace and Froum concluded in a meta-analysis on the survival of endosseous dental implants that membrane utilization is a useful adjunctive therapy that results in an increased survival rate of implants in the grafted maxillary sinus. ${ }^{9}$ It was also reported that the increase in implant survival could be explained by the higher percentage of bone. ${ }^{9,45}$ Surprisingly, this could not be confirmed by meta-analysis of the four selected papers. ${ }^{19-22}$

\section{Particulated and block grafting}

After statistical analysis, particulation of the bone graft seems to lead to a significantly lower amount of TBV, where there is no such evidence for bone blocks. In literature, it is reported that up to $33 \%$ of the autologous bone graft can resorb during the initial 6 months after sinus floor augmentation surgery. ${ }^{23,26,38,39}$ These processes of bone resorption and remodeling have a major influence on the clinical outcome and are described to be a continuous problem, as this effect of significant initial bone resorption may persist for years. ${ }^{31,40,41}$ Zerbo et al. performed sinus augmentation surgery using monocortical blocks of autologous chin bone to allow dental implant placement. ${ }^{19}$ As a result from biopsies taken at 2.5 and 7 months, the amount of nonvital bone decreased significantly with the time of healing, as it was progressively remodeled into new bone. ${ }^{19}$ Zijderveld et al. observed predominantly lamellar bone after a healing period of 6 months. ${ }^{33}$ Lorenzetti et al. performed unilateral augmentation with bone blocks or particulated bone originating from the chin. In the particulated subgroup, the healing period was reduced since the original compact bone structure had been removed by the particulation process. ${ }^{27}$ Chin bone blocks prevailed more over fibrous tissue ingrowth and proved to be more compact than particulated grafts. However, vitality within the cortical component varied to a great extent. $^{27}$ The chin bone blocks exhibited an increased bone quantity unlike the particulated chin bone and iliac bone blocks. ${ }^{27}$ A remarkable higher number of blood vessels was noted within the particulated bone graft than in block bone grafts. ${ }^{27}$ In a study of Consolo et al., biopsies were obtained after 4, 5, 6, and 7 months after iliac bone grafting. The amount of bone decreased over time, thus resorption was observed. $^{23}$ Also, these authors state that graft volume resorption seemed to occur during the early phase of healing. ${ }^{27}$ Pejrone et al. described that the amount of mineralized tissue was increased after 12 months compared with at baseline and measurements after 6 months, concluding that bone growth and remodeling had taken place. ${ }^{26}$ Further, histomorphometric results from Tadjoedin et al. showed that trabecular bone was present after 4 months in autologous iliac bone grafts. This bone contained viable osteocytes, was of a mature lamellar type, and showed a mature histological appearance. $^{28}$ In addition, bone volume continued to increase slightly at 5 and 6 months. ${ }^{28}$ In a study of van den Bergh et al., autogenous iliac crest grafts were used for sinus floor augmentation, from which after 6 months of healing core biopsies were obtained. In all five autogenous grafted sinuses, bone appearance was observed to be similar to normal maxillary bone, clinically as well as histologically. ${ }^{42}$ Gerressen et al. performed sinus floor augmentation procedures using grafts from the iliac crest consisting of purely cancellous bone or a composite of cancellous and cortical bone. Both resulted in reliably good bone quality suitable to allow osteointegration of dental implants. ${ }^{43}$ The purely cancellous bone graft, however, seemed to be superior to the mixture, although an average healing time of 6 months until implant insertion seems to be appropriate for both. ${ }^{43}$ Surprisingly, after statistical analysis of the literature, there was no significant evidence of resorption or differences in TBV in time. Szabo et al. stressed that although bone formation in the surgical area can be influenced by several factors, mainly individual patient factors strongly influence the fate of the various graft materials in the organism. ${ }^{44}$

\section{Histological section thickness}

Histomorphometry is the most frequently used method to evaluate the structural properties and the amount of TBV in biopsy samples, as obtained, for example, after maxillary sinus floor augmentations. Assessment is traditionally in two dimensions, which offer high spatial resolution and high image contrast. Section thickness, however, seemed to be a significant variable to TBV in histomorphometric coupes. In most studies, 5-10 $\mu \mathrm{m}$ thick histological sections were used, whereas in others $10-30 \mu \mathrm{m}$ or even $50 \mu \mathrm{m}$ thick sections were prepared. Further, no information was provided about the quality or the staining of the histological sections, which can also potentially influence the histomorphometric outcome.

\section{Summary}

In literature, no proof is available for an improved implant survival for the various donor sites. ${ }^{51}$ However, there are indications that bone harvested from an intraoral donor site will lead to a higher mineralization rate and increased incorporation compared with iliac bone grafting. ${ }^{17,31}$ The choice for selecting intraoral or iliac crest is made on a pure clinical basis. If a small amount of bone is required, an intraoral region is preferred. The additional advantage is that such a procedure can be performed under local anesthesia. If a large bone volume is needed, like for bilateral sinus augmentation procedures, then the iliac crest is the preferred donor site. Application of iliac bone grafts, however, will result in a significantly lower TBV as compared with bone grafts harvested from intraoral donor sites. There was no significant evidence whether "biopsy time," "immediate or delayed implant placement," "block grafting," or the "usage of a resorbable barrier membrane" had a positive or negative influence on the amount of TBV. However, it was reported that membrane utilization would increase implant survival due to the higher percentage of bone. 9,45 Surprisingly, this could not be confirmed by meta-analysis of the four selected papers. ${ }^{19-22}$ Further, patient age and histomorphometric slice thickness were significant variables on TBV.

\section{Conclusion}

"Age," "intra oral chin grafts," "intra oral miscellaneous grafts," "particulate," and "histological section thickness" were determined as significant variables on the histomorphometric outcome of TBV after sinus floor augmentation surgery using autologous bone. Only particulation of the bone graft leads to a significantly lower TBV, whereas the others lead to a significantly higher TBV. No correlation 
between TBV and time of graft healing could be found. Bone grafting from the iliac crest resulted in a significantly lower TBV compared with intraoral bone grafting. Although this is a clinically relevant finding, in case a considerable amount of bone is needed, like in the augmentation of the severely atrophic maxilla, harvesting of bone from the iliac crest still has to be considered the gold standard.

\section{Disclosure Statement}

No competing financial interests exist.

\section{References}

1. Kaufman, E. Maxillary sinus elevation surgery: an overview. J Esthet Restor Dent 15, 272, 2003.

2. Boyne, P.J., and James, R.A. Grafting of the maxillary sinus floor with autogenous marrow and bone. J Oral Surg 38, 613, 1980.

3. Misch, C.E. Maxillary sinus augmentation for endosteal implants: organized alternative treatment plans. Int J Oral Implantol 4, 49, 1987.

4. Esposito, M., Grusovin, M.G., Worthington, H.V., and Coulthard, P. Interventions for replacing missing teeth: bone augmentation techniques for dental implant treatment. Cochrane Database Syst Rev CD003607, 2006.

5. Esposito, M., Grusovin, M.G., Coulthard, P., and Worthington, H.V. The efficacy of various bone augmentation procedures for dental implants: a Cochrane systematic review of randomized controlled clinical trials. Int J Oral Maxillofac Implants 21, 696, 2006.

6. Tantum, H. Maxillary sinus implant reconstructions. Dentistry Clinical North America 30, 207, 1987.

7. Tong, D.C., Rioux, K., Drangsholt, M., and Beirne, O.R. A review of survival rates for implants placed in grafted maxillary sinuses using meta-analysis. Int J Oral Maxillofac Implants 13, 175, 1998.

8. Merkx, M.A., Maltha, J.C., and Stoelinga, P.J. Assessment of the value of anorganic bone additives in sinus floor augmentation: a review of clinical reports. Int J Oral Maxillofac Surg 32, 1, 2003.

9. Wallace, S.S., and Froum, S.J. Effect of maxillary sinus augmentation on the survival of endosseous dental implants. A systematic review. Ann Periodontol 8, 328, 2003.

10. Del, F.M., Testori, T., Francetti, L., and Weinstein, R. Systematic review of survival rates for implants placed in the grafted maxillary sinus. Int J Periodontics Restorative Dent 24, 565, 2004

11. Emmerich, D., Att, W., and Stappert, C. Sinus floor elevation using osteotomes: a systematic review and meta-analysis. J Periodontol 76, 1237, 2005.

12. Hurzeler, M.B., Kirsch, A., Ackermann, K.L., and Quinones, C.R. Reconstruction of the severely resorbed maxilla with dental implants in the augmented maxillary sinus: a 5-year clinical investigation. Int J Oral Maxillofac Implants 11, 466, 1996.

13. Jensen, O.T., Shulman, L.B., Block, M.S., and Iacono, V.J. Report of the Sinus Consensus Conference of 1996. Int J Oral Maxillofac Implants 13 Suppl, 11, 1998.

14. Lundgren, S., Moy, P., Johansson, C., and Nilsson, H. Augmentation of the maxillary sinus floor with particulated mandible: a histologic and histomorphometric study. Int J Oral Maxillofac Implants 11, 760, 1996.

15. Nkenke, E., Schultze-Mosgau, S., Radespiel-Troger, M., Kloss, F., and Neukam, F.W. Morbidity of harvesting of chin grafts: a prospective study. Clin Oral Implants Res 12, 495, 2001.

16. Nkenke, E., Radespiel-Troger, M., Wiltfang, J., SchultzeMosgau, S., Winkler, G., and Neukam, F.W. Morbidity of harvesting of retromolar bone grafts: a prospective study. Clin Oral Implants Res 13, 514, 2002.

17. Thorwarth, M., Srour, S., Felszeghy, E., Kessler, P., SchultzeMosgau, S., and Schlegel, K.A. Stability of autogenous bone grafts after sinus lift procedures: a comparative study between anterior and posterior aspects of the iliac crest and an intraoral donor site. Oral Surg Oral Med Oral Pathol Oral Radiol Endod 100, 278, 2005.

18. Aichelmann-Reidy, M.E., and Yukna, R.A. Bone replacement grafts. The bone substitutes. Dent Clin North Am 42, 491, 1998.

19. Zerbo, I.R., de Lange, G.L., Joldersma, M., Bronckers, A.L., and Burger, E.H. Fate of monocortical bone blocks grafted in the human maxilla: a histological and histomorphometric study. Clin Oral Implants Res 14, 759, 2003.

20. Peleg, M., Garg, A.K., Misch, C.M., and Mazor, Z. Maxillary sinus and ridge augmentations using a surface-derived autogenous bone graft. J Oral Maxillofac Surg 62, 1535, 2004.

21. Crespi, R., Vinci, R., Cappare, P., Gherlone, E., and Romanos, G.E. Calvarial versus iliac crest for autologous bone graft material for a sinus lift procedure: a histomorphometric study. Int J Oral Maxillofac Implants 22, 527, 2007.

22. Barone, A., Crespi, R., Aldini, N.N., Fini, M., Giardino, R., and Covani, U. Maxillary sinus augmentation: histologic and histomorphometric analysis. Int J Oral Maxillofac Implants 20, 519, 2005.

23. Consolo, U., Zaffe, D., Bertoldi, C., and Ceccherelli, G. Platelet-rich plasma activity on maxillary sinus floor augmentation by autologous bone. Clin Oral Implants Res 18, 252, 2007.

24. Raghoebar, G.M., Schortinghuis, J., Liem, R.S., Ruben, J.L., van der Wal, J.E., and Vissink, A. Does platelet-rich plasma promote remodeling of autologous bone grafts used for augmentation of the maxillary sinus floor? Clin Oral Implants Res 16, 349, 2005.

25. Thor, A., Franke-Stenport, V., Johansson, C.B., and Rasmusson, L. Early bone formation in human bone grafts treated with platelet-rich plasma: preliminary histomorphometric results. Int J Oral Maxillofac Surg 36, 1164, 2007.

26. Pejrone, G., Lorenzetti, M., Mozzati, M., Valente, G., and Schierano, G.M. Sinus floor augmentation with autogenous iliac bone block grafts: a histological and histomorphometrical report on the two-step surgical technique. Int J Oral Maxillofac Surg 31, 383, 2002.

27. Lorenzetti, M., Mozzati, M., Campanino, P.P., and Valente, G. Bone augmentation of the inferior floor of the maxillary sinus with autogenous bone or composite bone grafts: a histologic-histomorphometric preliminary report. Int J Oral Maxillofac Implants 13, 69, 1998.

28. Tadjoedin, E.S., de Lange, G.L., Holzmann, P.J., Kulper, L., and Burger, E.H. Histological observations on biopsies harvested following sinus floor elevation using a bioactive glass material of narrow size range. Clin Oral Implants Res 11, 334,2000

29. Zerbo, I.R., Zijderveld, S.A., de, B.A., Bronckers, A.L., de, L.G., ten Bruggenkate, C.M., and Burger, E.H. Histomorphometry of human sinus floor augmentation using a porous beta-tricalcium phosphate: a prospective study. Clin Oral Implants Res 15, 724, 2004. 
30. Kiebzak, G.M. Age-related bone changes. Exp Gerontol 26, 171, 1991.

31. Schlegel, K.A., Schultze-Mosgau, S., Wiltfang, J., Neukam, F.W., Rupprecht, S., and Thorwarth, M. Changes of mineralization of free autogenous bone grafts used for sinus floor elevation. Clin Oral Implants Res 17, 673, 2006.

32. Koole, R. Ectomesenchymal mandibular symphysis bone graft: an improvement in alveolar cleft grafting? Cleft Palate Craniofac J 31, 217, 1994.

33. Zijderveld, S.A., Zerbo, I.R., van den Bergh, J.P., Schulten, E.A., and ten Bruggenkate, C.M. Maxillary sinus floor augmentation using a beta-tricalcium phosphate (Cerasorb) alone compared to autogenous bone grafts. Int J Oral Maxillofac Implants 20, 432, 2005.

34. Scarano, A., Degidi, M., Iezzi, G., Pecora, G., Piattelli, M., Orsini, G., Caputi, S., Perrotti, V., Mangano, C., and Piattelli, A. Maxillary sinus augmentation with different biomaterials: a comparative histologic and histomorphometric study in man. Implant Dent 15, 197, 2006.

35. Le Lorc'h-Bukiet, I., Tulasne, J.F., Llorens, A., and Lesclous, P. Parietal bone as graft material for maxillary sinus floor elevation: structure and remodeling of the donor and of recipient sites. Clin Oral Implants Res 16, 244, 2005.

36. Crespi, R., Mariani, E., Benasciutti, E., Cappare, P., Cenci, S., and Gherlone, E. Magnesium-enriched hydroxyapatite versus autologous bone in maxillary sinus grafting: combining histomorphometry with osteoblast gene expression profiles ex vivo. J Periodontol 80, 586, 2009.

37. Hallman, M., Sennerby, L., and Lundgren, S. A clinical and histologic evaluation of implant integration in the posterior maxilla after sinus floor augmentation with autogenous bone, bovine hydroxyapatite, or a 20:80 mixture. Int J Oral Maxillofac Implants 17, 635, 2002.

38. Jensen, O.T., and Sennerby, L. Histologic analysis of clinically retrieved titanium microimplants placed in conjunction with maxillary sinus floor augmentation. Int J Oral Maxillofac Implants 13, 513, 1998.

39. Raghoebar, G.M., Batenburg, R.H., Timmenga, N.M., Vissink, A., and Reintsema, H. Morbidity and complications of bone grafting of the floor of the maxillary sinus for the placement of endosseous implants. Mund Kiefer Gesichtschir 3 Suppl 1, S65, 1999.

40. Verhoeven, J.W., Cune, M.S., Terlou, M., Zoon, M.A., and De, P.C. The combined use of endosteal implants and iliac crest onlay grafts in the severely atrophic mandible: a longitudinal study. Int J Oral Maxillofac Surg 26, 351, 1997.

41. Triplett, R.G., Schow, S.R., and Laskin, D.M. Oral and maxillofacial surgery advances in implant dentistry. Int J Oral Maxillofac Implants 15, 47, 2000.

42. van den Bergh, J.P., ten Bruggenkate, C.M., Groeneveld, H.H., Burger, E.H., and Tuinzing, D.B. Recombinant human bone morphogenetic protein-7 in maxillary sinus floor elevation surgery in 3 patients compared to autogenous bone grafts. A clinical pilot study. J Clin Periodontol 27, 627, 2000.

43. Gerressen, M., Hermanns-Sachweh, B., Riediger, D., Hilgers, R.D., Spiekermann, H., and Ghassemi, A. Purely cancellous vs. corticocancellous bone in sinus floor augmentation with autogenous iliac crest: a prospective clinical trial. Clin Oral Implants Res 20, 109, 2009.

44. Szabo, G., Suba, Z., Hrabak, K., Barabas, J., and Nemeth, Z. Autogenous bone versus beta-tricalcium phosphate graft alone for bilateral sinus elevations (2- and 3-dimensional computed tomographic, histologic, and histomorphometric evaluations): preliminary results. Int J Oral Maxillofac Implants 16, 681, 2001.

45. Tarnow, D.P., Wallace, S.S., Froum, S.J., Rohrer, M.D., and Cho, S.C. Histologic and clinical comparison of bilateral sinus floor elevations with and without barrier membrane placement in 12 patients: part 3 of an ongoing prospective study. Int J Periodontics Restorative Dent 20, 117, 2000.

46. Groeneveld, E.H., van den Bergh, J.P., Holzman, P., ten Bruggenkate, C.M., Tuinzing, D.B., and Burger, E.H. Histomorphometrical analysis of bone formed in human maxillary sinus floor elevations grafted with OP-1 device, demineralized bone matrix or autogenous bone. Comparison with non-grafted sites in a series of case reports. Clin Oral Implants Res 10, 499, 1999.

47. John, H.D., and Wenz, B. Histomorphometric analysis of natural bone mineral for maxillary sinus augmentation. Int J Oral Maxillofac Implants 19, 199, 2004.

48. Suba, Z., Takacs, D., Matusovits, D., Barabas, J., Fazekas, A., and Szabo, G. Maxillary sinus floor grafting with betatricalcium phosphate in humans: density and microarchitecture of the newly formed bone. Clin Oral Implants Res 17, 102, 2006.

49. Szabo, G., Huys, L., Coulthard, P., Maiorana, C., Garagiola, U., Barabas, J., Nemeth, Z., Hrabak, K., and Suba, Z. A prospective multicentre randomized clinical trial of autogenous bone versus beta-tricalcium phosphate graft alone for bilateral sinus elevation: histologic and histomorphometric evaluation. Int J Oral Maxillofac Implants 20, 371, 2005.

50. Turunen, T., Peltola, J., Yli-Urpo, A., and Happonen, R.P. Bioactive glass granules as a bone adjunctive material in maxillary sinus floor augmentation. Clin Oral Implants Res 15, 135, 2004.

51. Nkenke, E., and Stelzle, F. Clinical outcomes of sinus floor augmentation for implant placement using autogenous bone or bone substitutes: a systematic review. Clin Oral Implants Res 20, 124, 2009.

Address correspondence to: John A. Jansen, D.D.S., Ph.D. Department of Periodontology and Biomaterials Radboud University Nijmegen Medical Center PO Box 9101

Nijmegen $6500 \mathrm{HB}$ The Netherlands

E-mail: j.jansen@dent.umcn.nl

Received: August 14, 2009

Accepted: December 3, 2009

Online Publication Date: January 13, 2010 
